\title{
ANN MODELING AND MULTI OBJECTIVE OPTIMIZATION OF ELECTRICAL DISCHARGE MACHINING PROCESS
}

\begin{tabular}{|l|l|}
\hline Sanjeev Kumar Singh Yadav & Deepak Azad \\
Assistant Professor, MED,HBTI & M.Tech Scholar, HBTI \\
Kanpur, UP, India & Kanpur, UP, India \\
\hline
\end{tabular}

\begin{abstract}
This paper presents the modeling and optimization of EDM process for material removal rate and average surface roughness, during machining of nickel alloy material. The experiments were carried out on ZNC EDM, during the machining three input parameters were selected such as pulse current (I), pulse on- time (Ton) and duty factor (Df) in which each parameter was at three levels. The output parameters such as metal removal rate (MRR) and surface roughness (Ra) were selected for the work. In the present work the artificial neural network (ANN) has been developed for modeling and grey relational analysis (GRA) has been used for process optimization. The total degree of freedom (DOF) has been calculated without considering the effect of interaction among the different control factor. Based on DOM L $\mathrm{L}_{9}$ orthogonal array was selected for the process. The experimental data set were grouped into training data and testing data. The developed ANN architecture of 3-16-2 has been found to predict MRR and Ra. After optimization of the process parameters optimum parameters were determined as A3 (pulse current, 12A), B3 (pulse on time, $120 \mu \mathrm{s}$ ) and $\mathrm{C} 2$ (duty factor, 0.857).
\end{abstract}

KEYWORDS- Pulse Current, ANN, GRA, Duty factor

\section{INTRODUCTION}

Among all practically applicable Advanced Machining Processes (AMPs), EDM has attracted much research attention due to its broad industrial applications. EDM is extensively used in industry for machining difficult-to-machine electrically conductive materials with complex shapes which are widely used in tool and die manufacturing. At present, EDM is a widely accepted machining technique used for machining all type of electrically conductive materials including metals and alloys, conductive ceramics and composites. The Present paper describes processing and optimization of EDM process for Ni-alloy workpiece material. Nickel alloys and nickel-based super alloys are known for superior resistance to heat and corrosion as well as low thermal expansion properties. These properties make it useful in industries that require parts to retain stability as well as the ability to resist corrosion over a wide range of temperatures. Nickel Alloy extensively used in power generation industry and aerospace.

In this process sparking takes place between two electrodes a small amount of material is removed from each of the electrodes. This fact was realized and the attempts were made to hardness and control the spark energy to employ it for useful purpose, say, for machining of metals. While machining spark is produced between the two electrodes (tool and workpiece) and its location is determined by the narrowest gap between the two. Duration of each spark is very short. The entire cycle time is usually few micro-second. The frequency of sparking may be as high as thousands of sparks per second. The area over which a spark is effective (or spark radius) is also very small. However, temperature of the area under the spark is very high. As a result, the spark energy is capable of partly melting and partly vaporizing material from localized area on both the electrodes, i.e. workpiece and tool. The material is removed in the form of craters which spread over the entire surface of the workpiece [1]. Finally, the cavity produced in the workpiece is approximately the replica of the tool. To have machined cavity as replica of the tool, the tool wear should be zero. To minimize wear of the tool the operating parameters and polarity should be selected carefully. Particles eroded from the electrodes are known as debris. Usually the amount of material eroded from the tool surface is much smaller than that from the workpiece surface. In order to improve production rate and quality of machined part due to EDM process, it is necessary to select the most preferred machining conditions. It is difficult to get highest production rate due to complex EDM process because of their too many adjustable machining parameters. Two EDM process responses 
namely MRR for production rate of product and $R_{a}$ for quality of machined surface are prefer for study. However, the goal of achieving high MRR and low $\mathrm{R}_{\mathrm{a}}$ are conflicting in nature. Consequently, no particular combination of machining parameters can be proposed to give simultaneously the high MRR and low $R_{a}$. Many optimization techniques have been used by researchers for the determination of preferred input conditions for optimum value of output parameters.

Mahadavinejad [2] conducted experimentation on silicon carbide $(\mathrm{SiC})$ workpiece material and taken copper as a tool material. They have optimized the surface roughness and material removal rate of electro discharge machining parameters simultaneously. During experimentation they have taken Pulse current, pulse on time, and pulse off time as a input. Further, artificial neural network (ANN) with back propagation algorithm was used to model the process. A multi-objective optimization method, nondominating sorting genetic algorithm-II is used to optimize the process. Raghuraman et al. [3] have performed machining on Mild steel IS 2026 using copper electrode and investigated the optimal set of process parameters such as Pulse current, pulse on -time and off time in Electrical Discharge Machining (EDM) process to identify the variations in three performance characteristics such as rate of material removal, wear rate on tool, and surface roughness value on the work material. Grey relational analysis was used to optimize parameter. They have shown that the machining parameters for EDM were optimized for achieving the combined objectives of higher rate of material removal, lower wear rate on tool, and lower surface roughness value on the work material considered in this work. Chakradhar et al. [4] performed experiment on ECM machine. In this EN31 steel which is a high carbon steel used as workpiece material and electrolytic copper used as electrode. In this paper the input parameter are taken as electrolyte concentration, feed rate and applied voltage and output parameter material removal rate (MRR), overcut, cylindrical error and surface roughness (Ra). The Grey relational analysis was used to optimization the process. They have targeted performance characteristics, i.e. material removal rate can be maximized and the overcut, cylindrical error and surface roughness can be minimized through this method.

\section{EXPERIMENTAL WORK}

In the present research work all experiments are conducted on ZNC electric discharge machine, S 50 ZNC (die- sinking type) with servo-head (constant gap). The positive polarity was used for conduct the experiments. During experimentation commercial grade EDM oil (specific gravity) $=0.763$ (freezing point $=94^{\circ} \mathrm{C}$ ) was used as dielectric fluid. During the present experiment copper selected as tool material for machining. As Nickel alloy is a one of the super alloy due to broad application in advanced manufacturing industries it is selected for the present work.

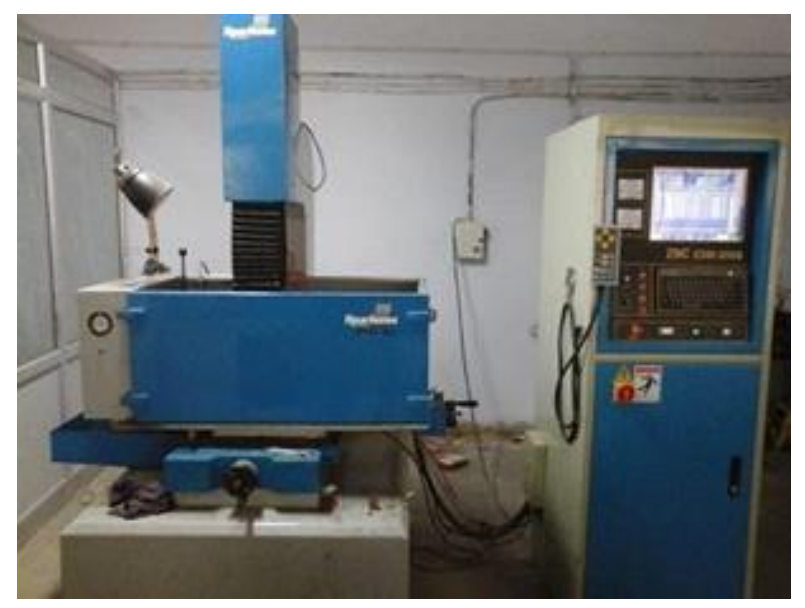

\section{FIGURE 1: PHOTOGRAPH OF ZNC EDM}

The size of Ni- alloy workpiece material is taken as $15 \times 15 \times 8 \mathrm{~mm}$. The properties of Ni-alloy workpiece material are shown in Table 1 and

\begin{tabular}{|c|c|}
\hline Properties & Value \\
\hline Density & $8.359 \mathrm{gm} / \mathrm{cm}^{3}$ \\
\hline Melting point & $1335^{\mathrm{O}} \mathrm{c}$ \\
\hline Boiling point & $2913^{\mathrm{O}} \mathrm{c}$ \\
\hline Thermal conductivity & $90.7 \mathrm{w} / \mathrm{m}^{\mathrm{O}} \mathrm{c}$ \\
\hline Hardness & $200 \mathrm{BHN}$ \\
\hline
\end{tabular}

photograph of die sinking ZNC EDM is shown in Fig.1.

TABLE 1: PROPERTIES OF WORK MATERIAL Based on degree of freedom the $\mathrm{L}_{9}$ orthogonal array were selected. Two repetitions for each experimentation was also performed. Before experimentation the selection of range of input parameters through pilot experimentation have been performed. After pilot experimentation the selected input parameter and there levels are shown in Table 2.

\section{TABLE 2: INPUT PARAMETERS AND THEIR} LEVELS 


\begin{tabular}{|l|c|c|c|}
\hline $\begin{array}{c}\text { Input } \\
\text { parameters }\end{array}$ & $\begin{array}{c}\text { Level } \\
\mathbf{1}\end{array}$ & $\begin{array}{c}\text { Level } \\
\mathbf{2}\end{array}$ & Level 3 \\
\hline Pulse Current & 6 & 9 & 12 \\
\hline Pulse on-time & 60 & 90 & 120 \\
\hline Duty factor & 0.571 & 0.857 & 0.937 \\
\hline
\end{tabular}

After selection of input parameters ranges the experimentation were performed on selected levels and results are tabulated in Table 3.

TABLE 3: RESPONSE TABLE FOR L 9 ARRAY

\begin{tabular}{|c|c|c|c|c|c|c|}
\hline $\begin{array}{l}\mathbf{E x} \\
\text { No. }\end{array}$ & $\begin{array}{l}\mathbf{M R}_{/ \mathbf{m i n}} \mathbf{R} \\
\mathbf{3}\end{array}$ & $\begin{array}{l}\mathbf{R a} \\
\mu \mathbf{m}\end{array}$ & $\begin{array}{l}\text { MRR1 } \\
\mathbf{m m}_{/ \mathrm{mi} \mathrm{n}}\end{array}$ & $\begin{array}{l}\text { Ra1 } \\
\mu \mathrm{m}\end{array}$ & $\begin{array}{l}\text { MRR } \\
\mathbf{3} \text { / } / \mathbf{m i}\end{array}$ & $\begin{array}{l}\mathrm{Ra} 2 \\
\mu \mathrm{m}\end{array}$ \\
\hline 1 & 2.12 & 5.57 & 2.15 & 5.87 & 2.03 & 6.10 \\
\hline 2 & 6.81 & 6.80 & 7.29 & 7.19 & 6.57 & 6.48 \\
\hline 3 & 14.03 & 7.78 & 13.71 & 7.67 & 13.48 & 7.09 \\
\hline 4 & 6.48 & 7.14 & 7.28 & 6.96 & 6.25 & 6.73 \\
\hline 5 & 22.01 & 8.55 & 23.96 & 8.63 & 22.80 & 7.78 \\
\hline 6 & 11.19 & 8.67 & 9.27 & 8.95 & 9.36 & 8.54 \\
\hline 7 & 24.03 & 7.29 & 25.27 & 8.15 & 22.88 & 7.01 \\
\hline 8 & 10.01 & 8.04 & 10.01 & 8.50 & 10.24 & 7.78 \\
\hline 9 & 24.60 & 9.39 & 24.06 & 10.07 & 21.37 & 8.90 \\
\hline
\end{tabular}

\section{MODILLING}

Modeling is the scientific way to study the process behavior which helps to get the better understanding of any complex process. In the present problem MATLAB toolbox used to perform ANN modeling. The multi-layer feed forward ANN consist of three parts: input layer, hidden layer, and the output layer were selected. The neurons between the layers are connected by the links having synaptic weights. The levenberg-marquardt back propagation algorithm is used to minimize mean square error. First, Microsoft excel worksheet used with total of 27 input and output experimental data and then imported the input, output and sample data in the workspace. Further, network create with varying neuron in hidden layer and trained the network after that performance was checked and network selected when mean square error was minimum. After appropriate training the network 3-16-2 found best. After training the data sample data is used to predict the output data. And finally predicted output data are obtained. The data used for selection of trained neural network is shown in Table 4.

\section{NEURAL NETWORK TOPOLOGY, MEAN SQUARE ERROR AND CORRELATION COEFFICIENTS}

The best process parameter setting for ANN modeling was selected with the help of full factorial method. The chosen optimal process parameters are Levenberg-Marquardt training algorithm, 16 nos. of hidden neurons MATLAB representation of ANN topology that has been utilized for modeling. Variation of MSE of training, validation and testing data set w.r.t. the epoch has been shown in Fig 2. Validation data set is used to stop the training process in early stopping criteria for providing better generalization. Fig 2 shows that the validation error is minimum at epoch 5. So the training was stopped at this point the weights and biases were used to model MRR and Ra. Weights and biases used for generating the ANN outputs which was be further used to do optimization process.

TABLE 4: TRAINING DATA SET

\begin{tabular}{|c|c|c|c|c|c|}
\hline $\begin{array}{r}\text { Exp. } \\
\text { No. }\end{array}$ & $\begin{array}{l}\text { Pulse } \\
\text { (A) }\end{array}$ & $\begin{array}{l}\text { Pulse } \\
\text { on } \\
\text { time } \\
(\mu \mathrm{s})\end{array}$ & $\begin{array}{l}\text { Duty } \\
\text { factor }\end{array}$ & $\underset{\mathrm{mm}^{3} / \mathrm{min}}{\mathrm{MRR}}$ & $\operatorname{Ra}(\mu \mathrm{m})$ \\
\hline 1 & 6 & 60 & 0.571 & 2.121 & 5.572 \\
\hline 2 & 6 & 90 & 0.857 & 6.815 & 6.807 \\
\hline 3 & 6 & 120 & 0.937 & 14.032 & 7.787 \\
\hline 4 & 9 & 60 & 0.857 & 6.488 & 7.147 \\
\hline 5 & 9 & 90 & 0.937 & 22.012 & 8.555 \\
\hline 6 & 9 & 120 & 0.571 & 11.193 & 8.675 \\
\hline 7 & 12 & 60 & 0.937 & 24.033 & 7.295 \\
\hline 8 & 12 & 90 & 0.571 & 10.013 & 8.045 \\
\hline 9 & 12 & 120 & 0.857 & 24.608 & 9.390 \\
\hline 10 & 6 & 60 & 0.571 & 2.157 & 5.870 \\
\hline 11 & 6 & 90 & 0.857 & 7.297 & 7.195 \\
\hline 12 & 6 & 120 & 0.937 & 13.713 & 7.670 \\
\hline 13 & 9 & 60 & 0.857 & 7.289 & 6.965 \\
\hline 14 & 9 & 90 & 0.937 & 23.962 & 8.630 \\
\hline 15 & 9 & 120 & 0.571 & 9.275 & 8.952 \\
\hline 16 & 12 & 60 & 0.937 & 25.278 & 8.155 \\
\hline 17 & 12 & 90 & 0.571 & 10.017 & 8.507 \\
\hline 18 & 12 & 120 & 0.857 & 24.065 & 10.072 \\
\hline 19 & 6 & 60 & 0.571 & 2.033 & 6.102 \\
\hline 20 & 6 & 90 & 0.857 & 6.571 & 6.480 \\
\hline 21 & 6 & 120 & 0.937 & 13.486 & 7.092 \\
\hline 22 & 9 & 60 & 0.857 & 6.252 & 6.735 \\
\hline 23 & 9 & 90 & 0.937 & 22.801 & 7.780 \\
\hline 24 & 9 & 120 & 0.571 & 9.367 & 8.547 \\
\hline 25 & 12 & 60 & 0.937 & 22.885 & 7.012 \\
\hline 26 & 12 & 90 & 0.571 & 10.244 & 7.780 \\
\hline 27 & 12 & 120 & 0.857 & 21.378 & 8.907 \\
\hline
\end{tabular}




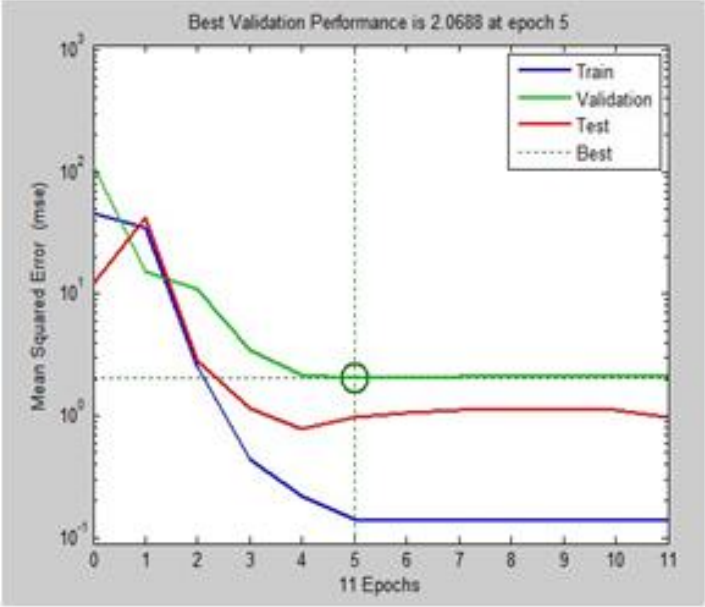

FIGURE 2- VARIATION OF MSE W.R.T. EPOCHS

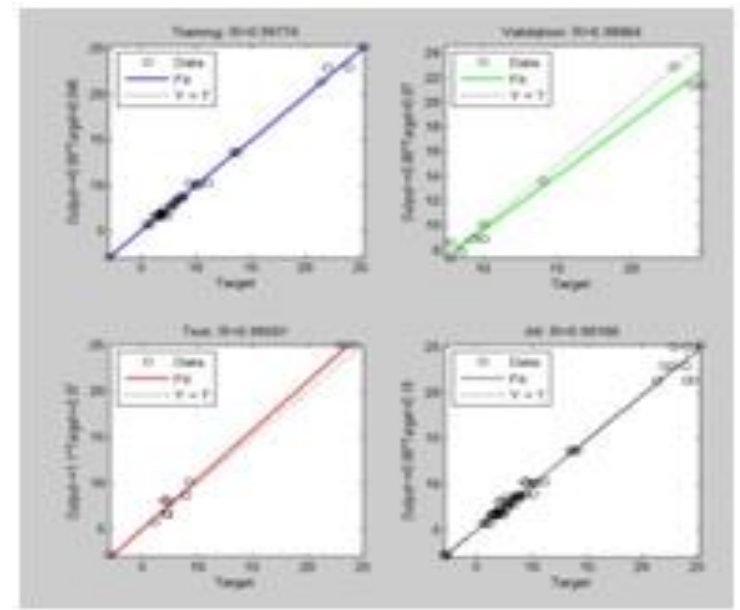

\section{FIGURE 3-CORRELATION COEFFICIENTS}

TABLE 5-ANN PREDICTED TABLE

\begin{tabular}{|c|c|c|c|l|l|}
\hline $\begin{array}{l}\text { Exp. } \\
\text { No. }\end{array}$ & $\begin{array}{l}\text { Pulse } \\
\text { current } \\
(\mathbf{A})\end{array}$ & $\begin{array}{l}\text { Pulse } \\
\text { on } \\
\text { time } \\
(\boldsymbol{\mu s})\end{array}$ & $\begin{array}{l}\text { Duty } \\
\text { factor }\end{array}$ & $\begin{array}{l}\text { MRR } \\
(\mathbf{m m} / \mathbf{m i n})\end{array}$ & $\begin{array}{l}\text { Ra } \\
(\boldsymbol{\mu m})\end{array}$ \\
\hline 1 & 6 & 60 & 0.57 & 2.237 & 5.75 \\
\hline 2 & 6 & 90 & 0.85 & 6.651 & 6.64 \\
\hline 3 & 6 & 120 & 0.93 & 13.518 & 7.38 \\
\hline 4 & 9 & 60 & 0.85 & 6.745 & 6.96 \\
\hline 5 & 9 & 90 & 0.93 & 22.935 & 8.58 \\
\hline 6 & 9 & 120 & 0.57 & 10.232 & 8.60 \\
\hline 7 & 12 & 60 & 0.93 & 25.046 & 8.16 \\
\hline 8 & 12 & 90 & 0.57 & 10.130 & 7.91 \\
\hline & & & & & \\
\hline
\end{tabular}

\begin{tabular}{|l|l|l|l|l|l|}
\hline 9 & 12 & 120 & 0.857 & 21.379 & 8.90 \\
\hline
\end{tabular}

\section{OPTIMIZATION}

Optimization refers to finding one or more feasible solutions which correspond to extreme values of one or more objectives. Because of such extreme values of optimal solution, optimization methods are of great importance in practice, particularly in engineering design and scientific experiments. When an optimization problem modeling a physical system involves only one objective function, the task of finding the optimal solution is called single-objective optimization. Whereas when an optimization problem involves more than one objective function, the task of finding one or more optimum solution is known as multi-objective optimization (MOO). Constraints optimization is important in practice, since most realworld optimization problems involve constraints restricting some properties of the system to lie within pre-specified limits. Convergence proofs and specialdynamic programming, geometric programming, stochastic programming, and various others. Not enough emphasis is usually given to multi-objective optimization. In MOO, a number of optimal solutions arising because of trade-off between conflicting objectives are important. GRA is well acceptable optimization method for advanced machining.

In GRA, black represent having no information and white represents having all information. A grey system has a level of information between black and white. When the range of sequences is large or the standard value is large, the function of factors is neglected. However, if the factors measured unit, goals and directions are different, the grey relational analysis might produce incorrect results. Therefore, original experimental data must be pre-processed to avoid such effects. Data pre-processing is the process of transforming the original sequence to a comparable sequence. For this purpose, the experimental results are normalized in the range of zero and one, the process is called grey relational generating.

STEP 1-Three different types of data normalization according to whether we require the Lower the better (LB), the higher the better (HB), and Nominal the better (NB). The normalization is taken by the following equations.

Lower the better (LB)

$$
X_{i}^{*}(k)=\frac{\max X_{i}(k)-X_{i}(k)}{\max X_{i}(k)-\min X_{i}(k)}
$$

Higher the better (HB) 


$$
X_{i}^{*}(k)=\frac{X_{i}(k)-\min X_{i}(k)}{\max X_{i}(k)-\min X_{i}(k)}
$$

Nominal the better (NB)

$$
X_{i}^{*}(k)=1-\frac{\left|X_{i}(k)-X_{d}\right|}{\max X_{i}(k)-X_{d}(k)}
$$

Where $i=1,2, \ldots, \mathrm{m} ; k=1,2, \ldots, \mathrm{n} ; X_{i}^{*}(k):$ the normalized value of the $k^{\text {th }}$ element in the $i^{\text {th }}$ sequence, $X_{d}(k)$ : the desired value of the $k^{\text {th }}$ quality characteristics, $\max X_{i}(k)$ is the largest value of $X_{i}(k)$, and $\min X_{i}(k)$ is the smallest value of $X_{i}(k), \mathrm{m}$ is the number of experiments and $\mathrm{n}$ is the number of quality characteristics.

TABLE 6: SIGNAL-TO-NOISE RATIO

\begin{tabular}{|l|l|l|l|l|}
\hline $\begin{array}{l}\text { Exp. } \\
\text { No. }\end{array}$ & \multicolumn{2}{|c|}{ Predicted } & \multicolumn{2}{c|}{ Salue } \\
\cline { 2 - 5 } & $\begin{array}{l}\text { MRR } \\
\left(\mathbf{m m}^{\mathbf{3}} / \mathbf{m i}\right.\end{array}$ & Ra $(\boldsymbol{\mu m})$ & $\begin{array}{l}\text { MRR } \\
\left(\mathbf{m m}^{3} / \mathbf{m i}\right.\end{array}$ & Ra $(\boldsymbol{\mu m})$ \\
\hline 1 & 2.237 & 5.754 & 6.993 & -15.199 \\
\hline 2 & 6.651 & 6.640 & 16.458 & -16.443 \\
\hline 3 & 13.518 & 7.388 & 22.618 & -17.370 \\
\hline 4 & 6.745 & 6.969 & 16.580 & -16.863 \\
\hline 5 & 22.935 & 8.583 & 27.210 & -18.673 \\
\hline 6 & 10.232 & 8.603 & 20.199 & -18.693 \\
\hline 7 & 25.046 & 8.163 & 27.975 & -18.237 \\
\hline 8 & 10.130 & 7.912 & 20.112 & -17.966 \\
\hline 9 & 21.379 & 8.909 & 26.599 & -18.996 \\
\hline
\end{tabular}

STEP 2: - In the 2nd step of the grey relational analysis, pre-processing of the data was first performed for normalizing the raw data for analysis. Yij is normalized as $\mathrm{Zij}(0 \leq \mathrm{Zij} \leq 1)$ by the followingformula to avoid the effect of adopting different units and to reduce the variability. The normalized output parameter corresponding to the larger-the-better criterion can be expressed as

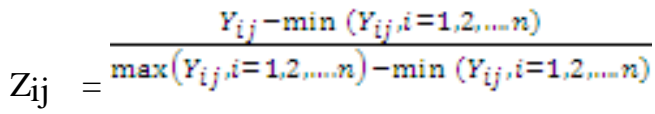

Then for the output parameters, which follow the lower-the-better criterion can be expressed as-

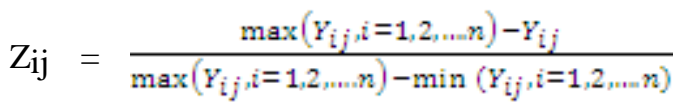

TABLE 7: NORMALIZED SIGNAL-TO-NOISE RATIO

\begin{tabular}{|l|l|l|l|l|l|}
\hline $\begin{array}{l}\text { Exp. } \\
\text { No. }\end{array}$ & $\begin{array}{l}\text { Pulse } \\
\text { current } \\
(\mathbf{A})\end{array}$ & $\begin{array}{l}\text { Pulse } \\
\text { on } \\
\text { time } \\
\end{array}$ & & $\begin{array}{l}\text { Duty } \\
\text { factor }\end{array}$ & \multicolumn{2}{|l|}{$\begin{array}{l}\text { Normalized S/N } \\
\text { ratio }\end{array}$} \\
\cline { 3 - 6 } & & & $\begin{array}{l}\text { MRR } \\
\left(\mathbf{m m}^{3} / \mathbf{m i n}\right)\end{array}$ & $\begin{array}{l}\text { Ra } \\
(\boldsymbol{\mu m})\end{array}$ \\
\hline 1 & 6 & 60 & 0.571 & 0 & 0 \\
\hline 2 & 6 & 90 & 0.857 & 0.4511 & 0.3276 \\
\hline 3 & 6 & 120 & 0.937 & 0.7447 & 0.5718 \\
\hline 4 & 9 & 60 & 0.857 & 0.4569 & 0.4382 \\
\hline 5 & 9 & 90 & 0.937 & 0.9635 & 0.9149 \\
\hline 6 & 9 & 120 & 0.571 & 0.6294 & 0.9202 \\
\hline 7 & 12 & 60 & 0.937 & 1 & 0.8001 \\
\hline 8 & 12 & 90 & 0.571 & 0.6252 & 0.7287 \\
\hline 9 & 12 & 120 & 0.857 & 0.9344 & 1 \\
\hline
\end{tabular}

STEP 3: A grey relational coefficient is calculated to display the relationship between the optimal and actual normalized experimental results. The grey relational coefficient can be expressed as

$$
\begin{aligned}
& r_{0, i}(k)=\frac{\Delta \min +\zeta \Delta \max }{\Delta_{0, i}(k)+\zeta \Delta \max }, \quad i=1, . m \\
& k=1, \ldots, n
\end{aligned}
$$

Where $r_{0, i}(k)$ is the relative difference of $\mathrm{k}^{\text {th }}$ element between comparative sequence $X_{i}$ and the reference sequence $X_{0}$ (also called as grey relational coefficient), $\Delta_{0, i}(k)$ is the absolute value of difference between $X_{O}(k)$ and $X_{i}(k)$,

$$
\begin{aligned}
& \Delta_{0 i}(k)=\left|X_{0}^{*}(k)-X_{i}^{*}(k)\right| \\
& \Delta \max =\max _{i} \max _{k}\left|X_{0}^{*}(k)-X_{i}^{*}(k)\right| \\
& \Delta \min =\min _{i} \min _{k}\left|X_{0}^{*}(k)-X_{i}^{*}(k)\right|
\end{aligned}
$$

$\zeta$ is a distinguishing or identification coefficient, and its value lie between zero and one. In general, it is set to 0.5 . 
TABLE 8: DEVIATION SEQUENCES

\begin{tabular}{|l|l|l|l|l|l|}
\hline & $\begin{array}{l}\text { Pulse } \\
\text { current } \\
(\mathbf{A})\end{array}$ & $\begin{array}{l}\text { Pulse } \\
\text { On } \\
\text { ime } \\
(\boldsymbol{\mu s})\end{array}$ & $\begin{array}{l}\text { Duty } \\
\text { factor }\end{array}$ & \multicolumn{2}{|c|}{ Deviation sequences } \\
\cline { 5 - 6 } & & & & $\begin{array}{l}\text { MRR } \\
\left(\mathbf{m m}^{3} / \mathbf{m i n}\right)\end{array}$ & $\begin{array}{c}\text { Ra } \\
(\boldsymbol{\mu m})\end{array}$ \\
\hline 1 & 6 & 60 & 0.571 & 1 & 1 \\
\hline 2 & 6 & 90 & 0.857 & 0.5489 & 0.6724 \\
\hline 3 & 6 & 120 & 0.937 & 0.2553 & 0.4284 \\
\hline 4 & 9 & 60 & 0.857 & 0.5431 & 0.5618 \\
\hline 5 & 9 & 90 & 0.937 & 0.0365 & 0.0851 \\
\hline 6 & 9 & 120 & 0.571 & 0.3706 & 0.0798 \\
\hline 7 & 12 & 60 & 0.937 & 0 & 0.1999 \\
\hline 8 & 12 & 90 & 0.571 & 0.3748 & 0.2713 \\
\hline 9 & 12 & 120 & 0.857 & 0.0656 & 0 \\
\hline
\end{tabular}

\section{TABLE 9: GREY RELATIONAL} COEFFICIENT

\begin{tabular}{|l|l|l|l|l|l|}
\hline $\begin{array}{l}\text { Ex } \\
\text { p. } \\
\text { No } \\
\cdot\end{array}$ & $\begin{array}{l}\text { Puls } \\
\text { curr } \\
\text { e } \\
\text { nt (A) }\end{array}$ & $\begin{array}{l}\text { Puls } \\
\text { e on } \\
\text { time } \\
(\boldsymbol{\mu s})\end{array}$ & $\begin{array}{l}\text { Duty } \\
\text { factor }\end{array}$ & \multicolumn{2}{|c|}{$\begin{array}{c}\text { Grey } \\
\text { relation }\end{array}$} \\
\cline { 4 - 6 } & & $\begin{array}{l}\text { MRR } \\
(\mathbf{m m} / \\
\text { min }\end{array}$ & Ra $(\boldsymbol{\mu m})$ \\
\hline 1 & 6 & 60 & 0.571 & 0.3333 & 0.3333 \\
\hline 2 & 6 & 90 & 0.857 & 0.4767 & 0.4265 \\
\hline 3 & 6 & 120 & 0.937 & 0.6620 & 0.5386 \\
\hline 4 & 9 & 60 & 0.857 & 0.4793 & 0.4709 \\
\hline 5 & 9 & 90 & 0.937 & 0.9320 & 0.8545 \\
\hline 6 & 9 & 120 & 0.571 & 0.5743 & 0.8624 \\
\hline 7 & 12 & 60 & 0.937 & 1 & 0.7144 \\
\hline 8 & 12 & 90 & 0.571 & 0.5715 & 0.6482 \\
\hline 9 & 12 & 120 & 0.857 & 0.8840 & 1 \\
\hline
\end{tabular}

Step 4: The grey relational grade was determined by averaging the grey relational coefficient corresponding to each performance characteristic. The overall performance characteristic of the multiple response process depends on the calculated grey relational grade. The grey relational grade can be expressed as $¥=\frac{1}{n} \sum_{k=1}^{n} \sum_{i}(\mathrm{k})$

Where, $¥ \mathrm{i}$ is the grey relational grade for the $\mathrm{j}^{\text {th }}$ experiment and $\mathrm{k}$ is the number of performance characteristics.
TABLE 9: GREY RELATIONAL GRADE

\begin{tabular}{|l|l|l|l|l|l|}
\hline $\begin{array}{l}\text { Ex } \\
\text { p. } \\
\text { No. }\end{array}$ & $\begin{array}{l}\text { Pulse } \\
\text { curre } \\
\text { nt } \\
\text { (A) }\end{array}$ & $\begin{array}{l}\text { P } \\
\text { ul } \\
\text { se } \\
\text { on }\end{array}$ & $\begin{array}{l}\text { Dut } \\
\text { y } \\
\text { fact } \\
\text { or }\end{array}$ & $\begin{array}{l}\text { Grey } \\
\text { relatio } \\
\text { nal } \\
\text { grade }\end{array}$ & Rank \\
\hline 1 & 1 & 1 & 1 & 0.3333 & 9 \\
\hline 2 & 1 & 2 & 2 & 0.4516 & 8 \\
\hline 3 & 1 & 3 & 3 & 0.6003 & 6 \\
\hline 4 & 2 & 1 & 2 & 0.4715 & 7 \\
\hline 5 & 2 & 2 & 3 & 0.8932 & 2 \\
\hline 6 & 2 & 3 & 1 & 0.7183 & 4 \\
\hline 7 & 3 & 1 & 3 & 0.8572 & 3 \\
\hline 8 & 3 & 2 & 1 & 0.6098 & 5 \\
\hline $\mathbf{9}$ & $\mathbf{3}$ & $\mathbf{3}$ & $\mathbf{2}$ & $\mathbf{0 . 9 4 2 0}$ & $\mathbf{1}$ \\
\hline
\end{tabular}

Step 5: Determination of the Optimal Factor and its level combination. The experimental design is orthogonal, it is possible to separate out the effect of each machining parameter on the grey relational grade at different levels. For example, the mean of the grey relational grade for the Pulse current at levels 1,2 and 3 can be calculated by averaging the grey relational grade for the experiments 1 to 3,4 to 6 , and 7 to 9 respectively. The mean of the grey relational grade for each level of the machining parameters is summarized. The larger the grey relational grade, the better is the multiple performance characteristics. However, the relative importance among the machining parameters for the multiple performance characteristics still needs to be known, so that the optimal combinations of the machining parameter levels can be determined more accurately.

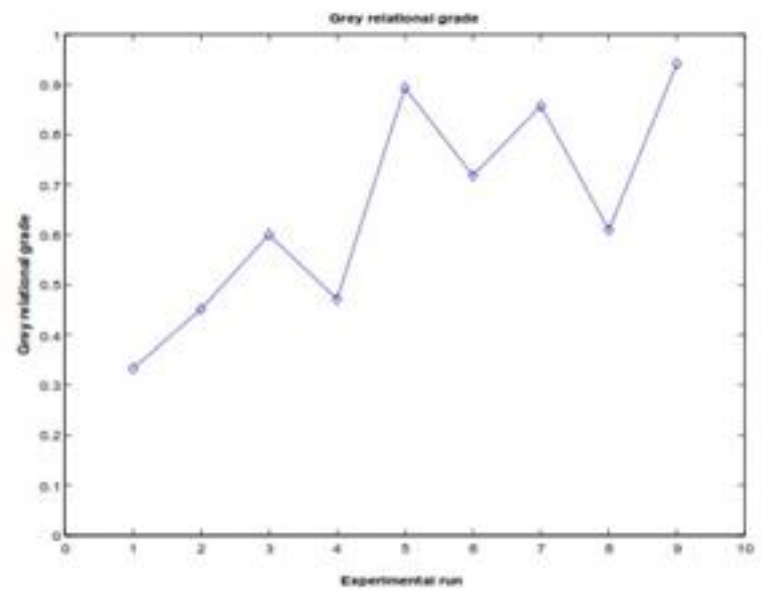

FIGURE 4: GREY RELATIONAL GRADE FOR MAXIMUM MRR AND MINIMUM Ra 
The larger the grey relational grade, the better is the multiple performance characteristics. However, the relative importance among the machining parameters for the multiple performance characteristics still needs to be known, so that the optimal combinations of the machining parameter levels can be determined more accurately. The optimal parameter combination was determined as A3 (pulse current, 12A), B3 (pulse on time, $120 \mu \mathrm{s})$ and $\mathrm{C} 2$ (duty factor, 0.857 ) which is shown in Table 10.

TABLE 10: THE MAIN EFFECTS OF THE FACTORS ON THE GREY RELATIONAL GRADE

\begin{tabular}{|l|l|l|l|l|l|}
\hline Parameter & Level 1 & Level 2 & Level 3 & $\begin{array}{l}\text { Max- } \\
\text { Min }\end{array}$ & Rank \\
\hline $\begin{array}{l}\text { Pulse } \\
\text { current }\end{array}$ & 0.4617 & 0.6955 & $\mathbf{0 . 8 0 3 0}$ & 0.3413 & 1 \\
\hline $\begin{array}{l}\text { Pulse-on- } \\
\text { time }\end{array}$ & 0.5552 & 0.6515 & $\mathbf{0 . 7 5 3 5}$ & 0.1983 & 3 \\
\hline $\begin{array}{l}\text { Duty } \\
\text { factor }\end{array}$ & 0.5538 & $\mathbf{0 . 7 8 3 6}$ & 0.6229 & 0.2298 & 2 \\
\hline
\end{tabular}
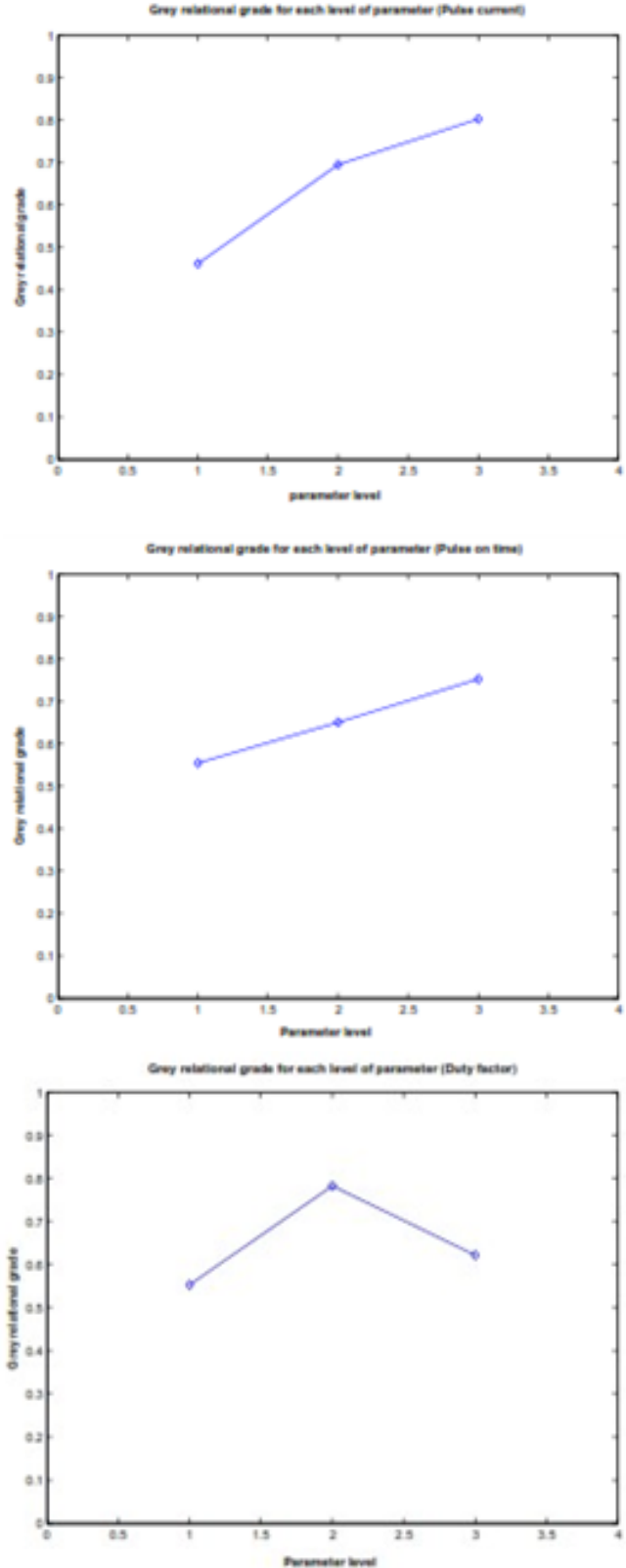

FIGURE 5: GREY RELATIONAL GRADE FOR EACH LEVEL OF PARAMETER

\section{CONFIRMING RESULTS}

The confirmation tests for the optimal parameters with its levels were conducted to evaluate quality characteristics for EDM of nickel alloy C-263. Table 5.9 shows highest grey relational grade, indicating the initial process parameter set of $\mathrm{A} 3 \mathrm{~B} 3 \mathrm{C} 2$ for the best multiple performance characteristics among the nine experiments. Table 11 shows the comparison of the 
experimental results for the optimal conditions (A3B3C2) with predicted results for optimal (A3B3C2) EDM parameters.

\section{TABLE 11: CONFIRMATION RESULTS}

\begin{tabular}{|l|c|c|}
\hline \multirow{2}{*}{} & \multicolumn{2}{|c|}{$\begin{array}{c}\text { Optimal process } \\
\text { parameters }\end{array}$} \\
\cline { 2 - 3 } & Experiment & Predicted \\
\hline Level & A3B3C2 & A3B3C2 \\
\hline $\begin{array}{l}\mathrm{MRR} \\
\left(\mathrm{mm}^{3} / \mathrm{min}\right)\end{array}$ & 21.378 & 21.379 \\
\hline $\mathrm{Ra}(\mu \mathrm{m})$ & 10.072 & 8.909 \\
\hline
\end{tabular}

\section{CONCLUSIONS}

Modeling and optimization of EDM process are very useful in academic as well as industries. In this work our investigation is machining of nickel alloy C-263 workpiece material using copper tool and then modeling and optimization are done. There are following conclusions have been made

1. The experimental results confirmed the validity of the used ANN for modeling and GRA for enhancing the machining performance and optimizing the parameters in EDM.

2. The experimental as well as predicted value at optimum level are nearly equal to each other and therefore confirm the success of experiment.

3. In the experiment it was found that MRR and $\mathrm{Ra}$ increases with an increase in Pulse current, pulse on time and duty factor.

4. There are various ANN architecture have been studied, and the architecture 3-16-2 was found to be best architecture.

5. Grey Relational Analysis associated with taguchi were applied in this work to improve the multi-response characteristics such as MRR and Surface Roughness for nickel alloy workpiece material during EDM process.

6. The optimal parameters combination was found as $\mathrm{A} 3 \mathrm{~B} 3 \mathrm{C} 2$ i.e. Pulse current at $12 \mathrm{~A}$, pulse on time at $120 \mu \mathrm{s}$ and duty factor at 0.857 .

\section{REFERENCES}

[1] Jain V.K (2002) "Advanced Machining Processes" Allied Publishers Pvt. Ltd. New Delhi, ISBN 817764-294-4.

[2] Mahdavi Nejad R.A(2011)"Modeling and Optimization of Electrical Discharge Machining of SiC Parameters, Using Neural Network and Nondominating Sorting Genetic Algorithm (NSGA II)" Materials Sciences and Applications.2, 669-675.

[3] Raghuraman S, Thiruppathi K, Panneerselvam T, Santosh S (2013) "optimization of EDM parameters using taguchi method and grey relational analysis for mild steel is 2026 " International Journal ofInnovative Research in Science, Engineering and Technology,Vol. 2, Issue 7, ISSN: 2319-8753.

[4] Chakradhar D and Gopal A. V (2011) "Multiobjective optimization of electrochemical machining of EN31 steel by grey relational analysis" International Journal of modelling and optimization, vol. 1 no 2 .

[5] Balasubramanian S and Ganapathy S (2011) "Grey Relational Analysis to determine optimum process parameters for Wire Electro Discharge Machining (WEDM)" International Journal of Engineering Science and Technology Vol. 3 No. 1 ISSN: 0975-5462

[6] Rajyalakshmi G and Ramaiah P. V (2012) "Simulation, modelling and optimization of process parameters of wire EDM using taguchi-grey relational analysis" International Journal of Advanced and innovative research ISSN: 2278-7844.

[7] ShandilyaP and TiwariA (2014) "Artificial Neural Network Modeling and Optimization using Genetic Algorithm of Machining Process" Journal of Automation and Control Engineering Vol. 2, No. 4.

[8] Mandal D, Pal S. K and Saha P (2007) "Modeling of electrical discharge machining process using back propagation neural network and multi-objective optimization using non-dominating sorting genetic algorithm-II" Journal of Materials Processing Technology 186 154-162.

[9] Assarzadeh S, and Ghoreishi $M$ (2008) "Neuralnetwork-based modeling and optimization of the 
electro-discharge machining process" International Journal of Advanced Manufacturing Technology 39:488-500.

[10] Raghav G, Kadam B.S, Kumar M (2013) "Optimization of Material Removal Rate in Electric Discharge Machining Using Mild Steel" International Journal of Emerging Science and Engineering Volume-1, Issue-7 ISSN: 2319-6378. 